\title{
The influence of fluorine on municipal sewage biological treatment
}

\author{
Joanna Gluzińska, Marian Legutko \\ Institute of Inorganic Chemistry, ul. Sowińskiego 11, 44-101 Gliwice, Poland, e-mail: jgluz@ichn.gliwice.pl
}

\begin{abstract}
The authors examined the influence of fluorine as a factor disrupting the processes of municipal sewage biological treatment. Sodium fluoride was introduced to a municipal plant sewage treated in an oxygen zone, acting as a simulator of uncontrolled industrial sewage discharge. The influence of fluoride ion concentration and the duration of sewage treatment on its biological purification processes were examined. Also, the dependencies of the direction of changes in inorganic nitrogen connections, phosphorus concentration, COD and fluorine on the initial fluorine compound content in the purified sewage were determined. Research samples of the municipal sewage were drawn at the opening of the oxygen zone in a typical municipal sewage treatment plant (RLM > 100 000) employing intensified biogenic substance removal.
\end{abstract}

Keywords: : oxygen processes, activated sludge, environment protection.

Presented at VII Conference Wasteless Technologies and Waste Management in Chemical Industry and Agriculture, Międzyzdroje, 12 - 15 June, 2007.

\section{INTRODUCTION}

At present, the main globally used sewage treatment method is the activated sludge method. Biological sewage treatment has been performed for a long time and is conducted in numerous ways - depending on the construction of bioreactors, regional and climatic conditionings, etc. still, there are general aspects constituting the subject of the research ${ }^{1}$. Activated sludge microorganisms are very sensitive to the influence of factors interfering with their life processes. The fundamental problems of biological treatment embrace uncontrolled industrial sewage discharges, carrying elements and compounds lethal to bacteria used at sewage treatment plants ${ }^{2}$. Applying the biochemical and partly physical processes to sewage treatment makes it possible to obtain the lowering of the organic substance load in the sewage. They are usually used as a consecutive stage of treatment in the case the previously used methods have failed to ensure the appropriate quality of water discharged into the tanks. Biological purification proceeds both under oxygen and hypoxic as well as the anaerobic conditions, and consists in the oxidization and mineralization of organic compounds contained in the sewage with the participation of micro - and macro - organisms. These organisms use the compounds present in the sewage as nourishment and as the basis of metabolism. The purification principle is the same as in the case of natural self-purification of water bodies.

The difference lies in creating the optimal conditions for the process (the presence of oxygen, nourishment, mechanical blending temperature, $\mathrm{pH}$ ), which increase its speed and efficiency.

In all biological sewage treatment methods the following processes occur?:

- decomposition of inorganic substances to $\mathrm{CO}_{2}, \mathrm{H}_{2} \mathrm{O}$ and $\mathrm{NH}_{3}$;

- nitrification, i.e. oxidizing $\mathrm{NH}_{3}$ to nitrites (using Nitrosomonas), and then to nitrates (using Nitrobacter);

- denitrification, i.e. transforming nitrates into the form of gaseous nitrogen $\left(\mathrm{N}_{2}\right)$.

To ensure the correctness of biological sewage treatment processes, creating suitable conditions is vital, including delivering the activated sludge microorganisms a suitable amount of energy in the form of easily assimilable organic carbon compounds; and maintaining the optimal temperature and environmental reaction. The changes of the above mentioned parameters resulting from the altering composition of the sewage entering the plant may cause considerable disturbances in the operation of the plant. Determining the maximal loads of potential contaminations (fluorine, acids, lye, temperature) introduced into the living sewage from industrial plants (a simulation of industrial sewage discharge at a municipal sewage treatment plant) is vital as well.

The aim of the research was to state whether and how fluorine ions influence the course of biological sewage treatment in the oxygen zone of municipal WWTP. The authors intended to establish an admissible threshold of fluorine ions concentration.

\section{EXPERIMENTAL}

The research material - activated sludge suspensionwas drawn from a biological reactor of a typical municipal sewage treatment plant with intensified the biogenic substances removal (RML > 100 000) from the aerobic section. Sodium fluoride (NaF, the concentration of $19 \mathrm{gF} /$ L) was used as a source of fluoride ions in the research. The sewage was drawn from the opening part of an oxygen chamber at a municipal sewage treatment plant, from the depth of about $1 \mathrm{~m}$, in the morning hours, the temperatures of both the air and the sample registered at the moment of drawing. The sewage was driven to the Institute and moved to the reactor chamber (KLF 2000 Bioengineering), its working capacity being $3.0 \mathrm{~L}$.

The research was conducted in 7 measurement series. In each series the most important contamination indicators were marked (COD, reaction, the content of: general, ammonium, nitrate and nitrite nitrogen, the content of phosphorus and fluorine, the concentration of dissolved oxygen and temperature). The temperature of the sewage sample inserted into the reactor was maintained between $22-23^{\circ} \mathrm{C}$. NaF solution was administered in such quantity so as to obtain the estimated initial concentration of fluoride ions, $25-150 \mathrm{mg} / \mathrm{L}$, different in each measurement series. During the whole test the sewage was aerated 
(the air was inserted with a pump at the bottom of the reactor), in order to obtain the concentration of oxygen dissolved on the level required for the aerobic zone, over $0.5 \mathrm{mgO}_{2} / \mathrm{L}$. After 1.5 hour a sample of $200 \mathrm{ml}$ was drawn in order to make a series of markings just like for crude sewage. Another series of markings was done after the test was finished, that is after $3 \mathrm{hrs}$ since its beginning. The concentration of dissolved oxygen was marked every 30 minutes with an oxygen probe.

In series I (samples 1 - 3) no sodium fluoride was introduced, the series being treated as a point of reference for the assessment of the research results on the influence of fluorine presence on the process of sewage treatment in other series.

\section{RESULTS AND DISCUSSION}

The presented graphs (Figure 1 and Figure 2) show a steady tendency to oxidize the ammonium form of nitrogen (the value of $\mathrm{N}-\mathrm{NH}_{4}$ concentration was decreasing at all stages of the particular research series). This means that the form of nitrogen connection changed from ammonium into nitrite ones. It is most likely connected with the correct metabolic process in the cells of Nitrosomonas bacteria being one of the elements of the first trophic level of the activated sludge trophic pyramid. The gradual increase of the concentration of nitrogen in the nitrate form proves the further faultlessness of the oxygen sewage treatment process. Series V is an exception - despite the decrease of the concentration of the ammonium form (at the first stage) corroborating the oxygen process, a fall in nitrate nitrogen concentration was observed in the sewage.

It may prove the disruption of Nitrobacter bacteria life processes, which in the group of activated sludge organisms are responsible for oxidizing nitrite forms into nitrate ones. What may have occurred is the denitrification, which manifests itself by a decrease of oxygen concentration and as a consequence, by the reduction of nitrite forms of nitrogen into a gaseous form.

During the research the process changes in the oxidization degree of organic substance present in the sewage were observed. These changes are illustrated by the COD curve (Figure 1 and Figure 2).

In series II - VI an increase of COD value was observed, the biggest one occurring in series V. It may confirm the malfunctioning of the microorganisms, and even their gradual death, manifesting itself through the increase of organic matter concentration and the decrease of the effectiveness of nitrogen oxidizing process. The COD value increase was clearly related to the decrease of the nitrate nitrogen concentration in the sewage. In all test series a significant decrease of phosphorus concentration in the purified sewage was observed.

What is responsible for the assimilability of this biogene in the oxygen zone during the biological sewage treatment are the microorganisms present in the activated sludge: Pseudononas, Aeromonas and Acinetobacter. It seems that not only proper functioning of these bacteria influences the degree of the sewage purification from phosphorus compounds. It was observed that the degree of phosphorus removal increased along with the increase in fluorine concentration in the sewage: from the value of $13 \%$ in series II (the initial concentration of fluorine being
$25 \mathrm{mgF}^{-} / \mathrm{L}$ ) to $87.9 \%$ in series VII (the initial fluorine concentration of $150 \mathrm{mgF}^{-} / \mathrm{L}$ ).

The concentration of fluorine in municipal sewage is maintained at the level of $0.1-0.3 \mathrm{mg} / \mathrm{L}$. The authors of the research intended to examine the influence of a relatively high concentration of fluorine, resulting from the uncontrolled discharge of highly loaded inorganic contaminations of industrial sewage, e.g. from fertilizer industry. The initial fluorine concentration was differentiated between $25-150 \mathrm{mg} / \mathrm{L}$. During the oxygen sewage treatment process this concentration decreased, and the degree of sewage purification from fluorine rose proportionally to the amount of fluoride ions introduced into the sewage (series II - about 5\%, series VII - about 40\%). However, the high initial fluorine concentration converted into its final, not very high value in purified sewage. An exception is series II where the concentration of fluorine in the purified sewage was below $24 \mathrm{mg} / \mathrm{L}$.

According to the authors the research results allow to draw a conclusion that the increased presence of fluoride ions influences the biological sewage treatment process in an oxygen zone. However, it is hard to determine clearly the positive or negative influence of fluoride ions on the purification process. On the other hand, fluctuations of the concentration values of two other contamination indicators were observed, as well as the insufficient effectiveness of the removal of the fluorine itself.

What the authors observed during the research was a simultaneous increase of fluorine removal degree from the sewage - rising with the increasing number of introduced F ions - and the increase of phosphorus removal degree. No sludge analyses were carried out in the research, however it seems that the sludge may contain traces of inorganic phosphorus and fluorine connections.

Disruptions in the transformations of nitrogen forms observed in series $\mathrm{V}$ of the tests seem to prove that with the fluorine concentration of about $100 \mathrm{mg} / \mathrm{L}$ metabolic processes in the cells of microorganisms present in the activated sludge organism group are subject to considerable inhibition or complete suppression. The above results in a decrease in nitrate nitrogen content, as well as in the lowering of ammonium nitrogen concentration and noticeable increase of COD value.

What deserves attention is the fact that the further increase of fluorine concentration in the sewage changes the tendencies in the course of the process. For 125 and $150 \mathrm{mgF}^{-} / \mathrm{L}$ concentrations there occurs intensification of nitrogen and organic compounds oxidizing processes (an increase of $\mathrm{N}-\mathrm{NO}_{3}$ concentration, a decrease in the value of the COD indicator). The above might be caused by the precipitation of the sludge containing organic phosphorus-fluoride connections. A qualitative X-ray analysis of the precipitated sludge might confirm this.

\section{CONCLUSIONS}

By simulating a combination of municipal sewage with the sewage coming from an uncontrolled discharge of highly loaded inorganic contaminations of industry sewage, eg. from fertilizer industry, the authors assessed the influence of fluoride ions on the process of biological sewage purification in an aerobic chamber. The diversified initial concentration of fluoride ions altered the course 
a)

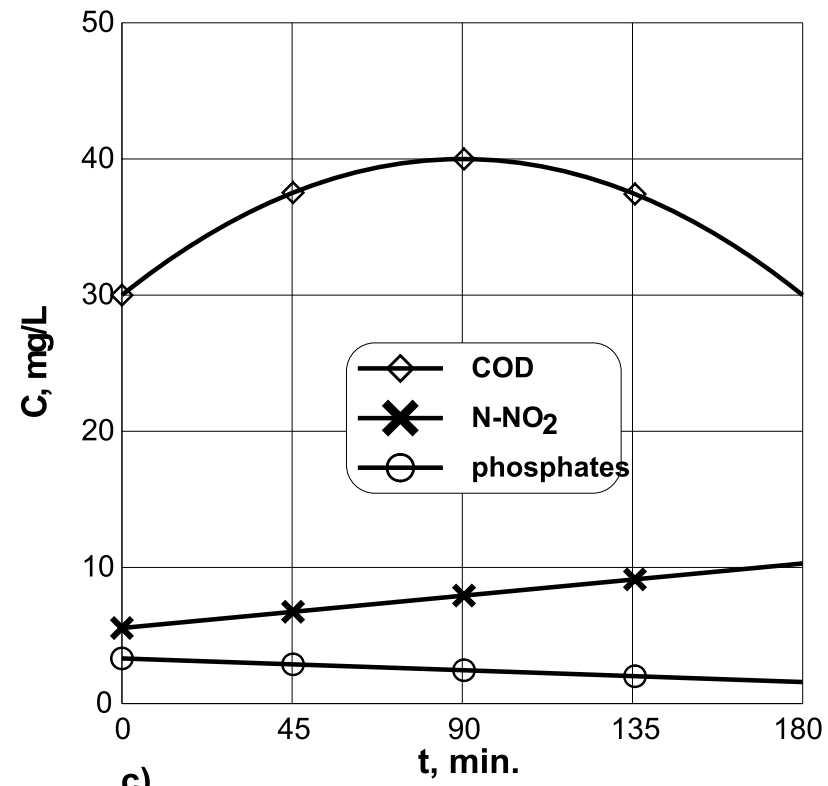

c)

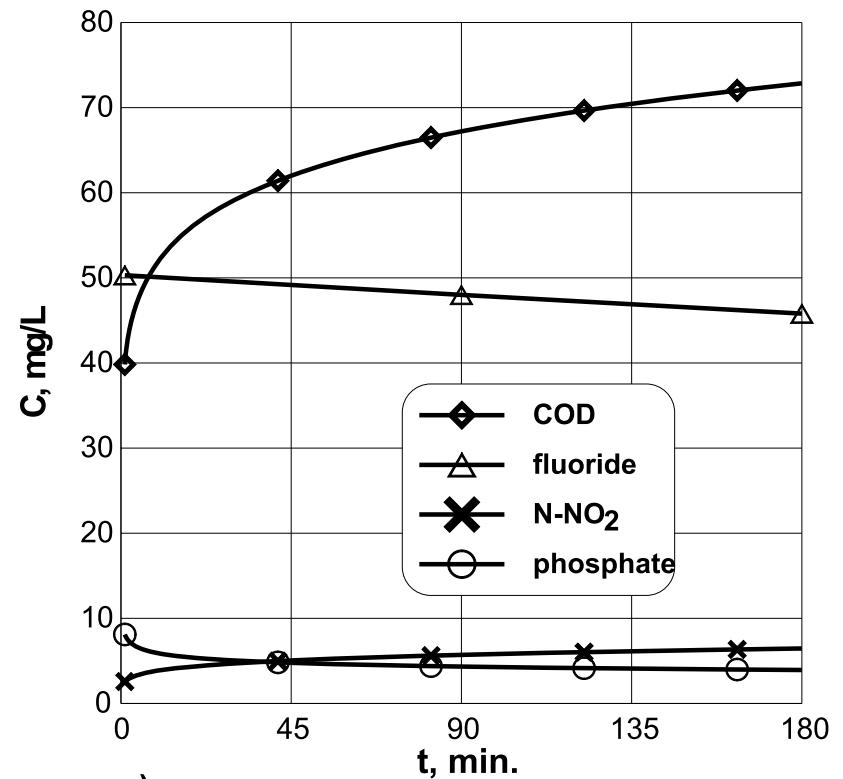

e)

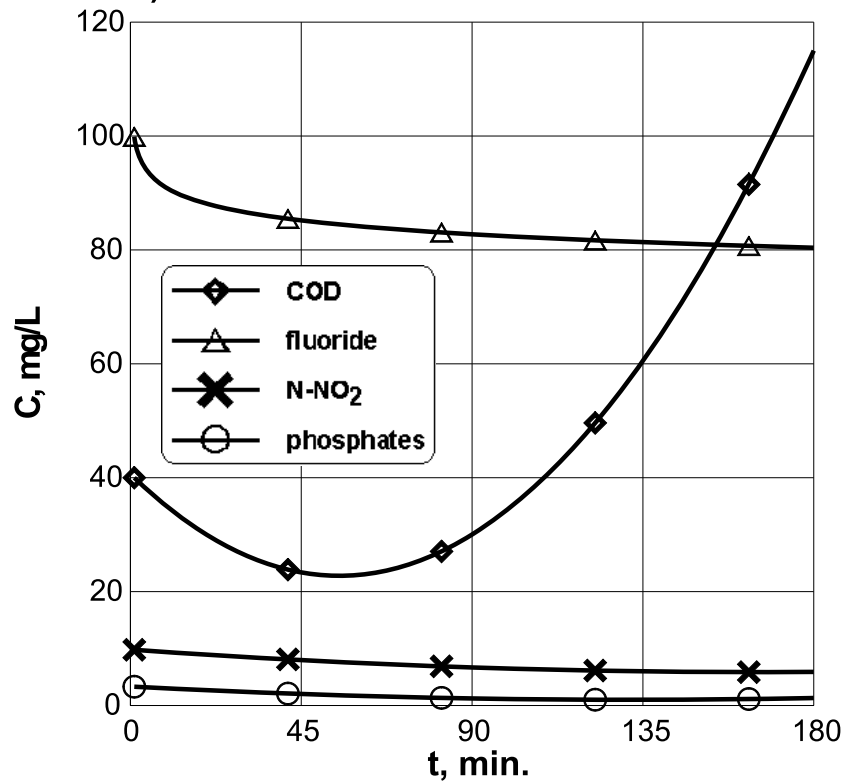

b)
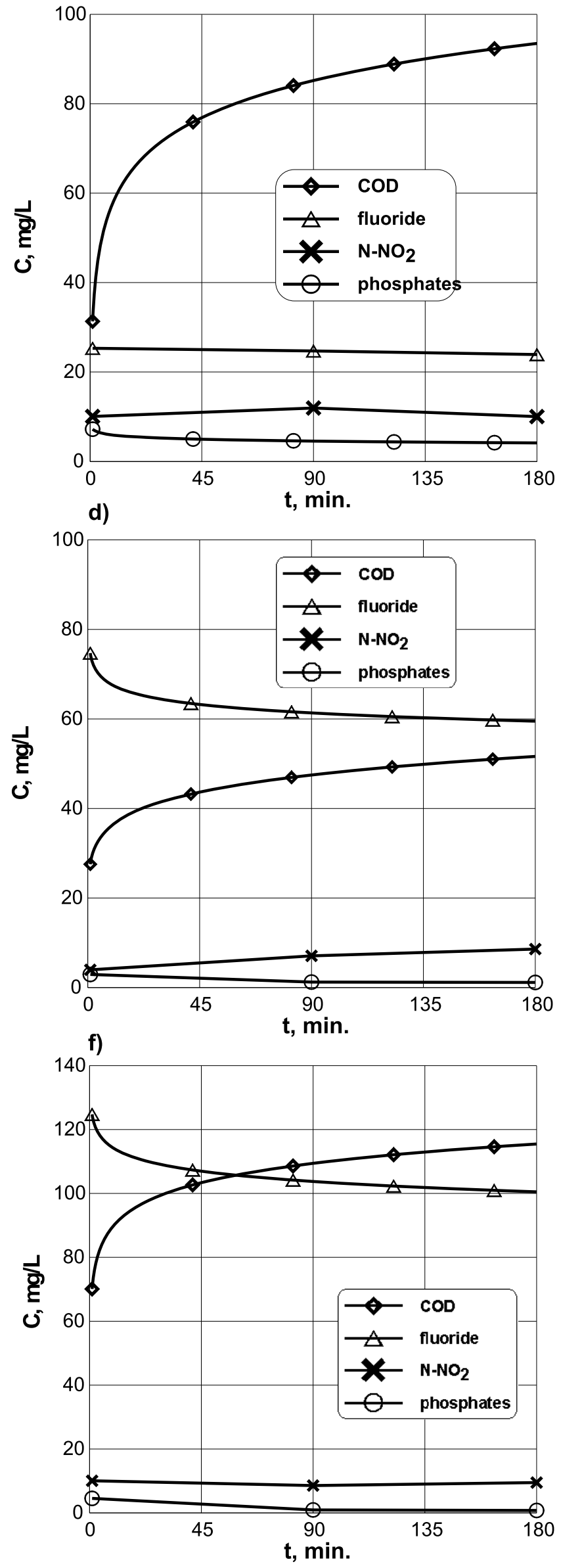

Figure 1. Changes in the basic values of contamination indicators during the biological sewage treatment in the oxygen zone; a) series I, b) series II, c) series III, d) series IV, e) series V, f) series VI 


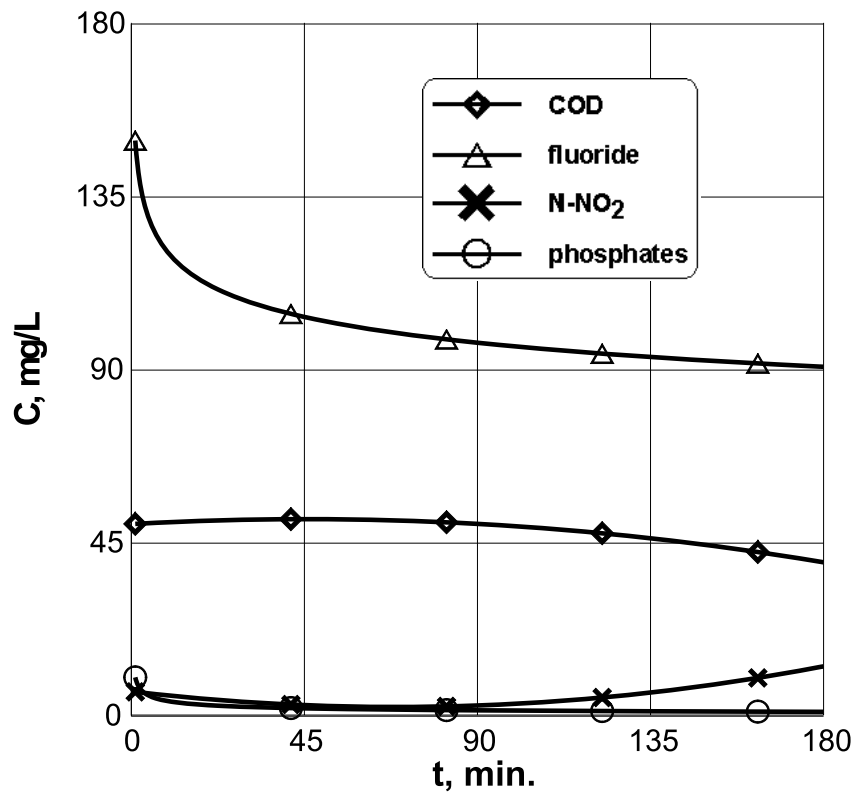

Figure 2. Changes in the basic values of contamination indicators during the biological sewage treatment in the oxygen zone - series VII

of the process decidedly. The character of these changes obviously depends on the range of the concentration values. With the initial fluorine concentration of less than 75 $\mathrm{mg} / \mathrm{L}$ the changes were minor. For concentrations ranging from 75 to $100 \mathrm{mgF}^{-} / \mathrm{L}$ the character of the changes was infavourable as hindering of the sewage purification oxygen process could be observed (an increase of the COD concentration value and a decrease of $\mathrm{N}-\mathrm{NO}_{3}$ concentration). Within $100-150 \mathrm{mgF}^{-} / \mathrm{L}$ biological processes seemed to proceed simultaneously with the chemical process of the contaminations precipitation.

A great majority of tests allow one to claim the faultlessness of the nitrification process, the proof being a growing value of nitrate nitrogen. Only in the case of concentrations ranging from $75-100 \mathrm{mgF}^{-} / \mathrm{L}$ a decrease of the nitrification efficiency was observed. The results of the analyses (a decrease in $\mathrm{N}-\mathrm{NO}_{3}$ and $\mathrm{N}-\mathrm{NH}_{4}$ concentrations) permit to draw a conclusion concerning the change of the character of the process (denitrification). Increasing fluorine concentration in the sewage positively influences the efficiency of phosphorus compounds removal. It would be very advantageous from the perspective of biogenic substances (mainly phosphorus compounds), however, the number of fluoride ions remaining in the purified sewage is highly unsatisfactory. What occurs for high fluorine concentrations (over $100 \mathrm{mg} / \mathrm{L}$ ) is presumably the bonding of fluoride ions in both the organic and inorganic connections, with their simultaneous precipitation in the sewage sludge. The conducted research allows one to draw a conclusion of the infavourable influence of high fluoride ions concentrations on the course of biological sewage treatment in the oxygen zone of a municipal sewage purification plant. It can be said that the highest concentration of this ion should not exceed the value of $25 \mathrm{mg} / \mathrm{L}$. Uncontrolled discharge of sewage of higher fluoride concentration requires application of chemical precipitation before entering the sewage into a biological reactor.

\section{LITERATURE CITED}

(1) Serafin M., Tabernacki J.: Biochemiczne usuwanie nadmiaru azotu i fosforu ze ścieków w świetle doświadczeń duńskich, Gaz, Woda i Technika Sanitarna, 1992, 9, 217-221.

(2) Hartmann L.: Biologiczne oczyszczanie ścieków, Wydawnictwo Instalator Polski, Warszawa, 1996.

(3) www.chem.uw.edu.pl/people/AMyslinski/cw13/ ins13.htm, 2006. 